Portland State University

PDXScholar

$5-22-2020$

\title{
The Role of a Nurse in the End-of-Life Experience of People Who Don't Have Family
}

Laurynn E. Leonard

Portland State University

Follow this and additional works at: https://pdxscholar.library.pdx.edu/honorstheses

Let us know how access to this document benefits you.

\section{Recommended Citation}

Leonard, Laurynn E., "The Role of a Nurse in the End-of-Life Experience of People Who Don't Have Family" (2020). University Honors Theses. Paper 901.

https://doi.org/10.15760/honors.923

This Thesis is brought to you for free and open access. It has been accepted for inclusion in University Honors Theses by an authorized administrator of PDXScholar. Please contact us if we can make this document more accessible: pdxscholar@pdx.edu. 
The Role of a Nurse in the End-of-Life Experience of People Who Don't Have Family

By

Laurynn Leonard

An undergraduate honors thesis submitted in partial fulfilment of the requirements for the degree

of

Bachelor of Science

In

University Honors

And

Biology and Science

Thesis Advisor

Diana White, Ph.D

Portland State University 


\section{Abstract}

Childlessness is becoming more common and this has important implications for those at the end of life. Literature on hospice and care of people at the end of life is heavily focused on family. A major emphasis of end-of-life care is how to support family members, the family role in providing support, and the influence the family has on the patient. Little research, however, has been conducted to determine the difference in how hospice and palliative care can best be provided to those without a spouse, adult children, or siblings compared to those with family support. This research aims to answer the following questions, "Do the needs and care of people with no family differ from those with family?" If so, "What is the role of nurses in palliative care with individuals without family, and how does the nurse-patient relationship influence their endof-life experience?" This research, therefore, will explore aspects of the nurse-resident relationship that play a role in providing quality care to this underrepresented demographic. This exploratory research will be conducted through interviews with residents with no close family along with the nurses involved in their care. Nurses will be shadowed so their relationship with residents can be observed. This research was proposed, reviewed and approved by the Institutional Review Board of Portland State University but was not able to be implemented due to restrictions of COVID-19; this research has been postponed to a further date. This paper will discuss the methods and next steps to complete this research.

\section{$\underline{\text { Background }}$}

For centuries, the dying process occurred in the comfort of home surrounded by family and loved ones. The rate of death in hospitals accelerated by the mid-twentieth century with the goal to keep individuals alive as long as possible (Gawande, 2014). Although this extended the length of life, their quality of life was reduced because it focused more on the physical care and 
less on the mental and emotional process of dying. Hospice care was introduced in the 1970s as an alternative to support decisions made by patients to accept their terminal illnesses and stop receiving clinical treatment. Hospice care emphasizes minimizing pain and keeping patients comfortable. In the majority of hospice cases, nurses, doctors, healthcare providers and volunteers all go to the patient's own home to provide their services alongside the family. In cases when the patient has no family, these people are often the only ones to provide care at the end-of-life. Although friends and distant relatives may be in contact and provide occasional company, they typically do not offer the around the clock, hands-on aid that is needed in addition to the support from the hospice team. A hospice patient cannot provide their own care and hiring a caregiver can become too burdensome and expensive. This is why oftentimes people without family choose to live in an assisted living facility (Mark, 2018).

Although hospice is all about making the end-of-life process as comfortable as possible, it is highly focused on family who often have a heavy influence on medical decisions and provide much of the emotional support. Hospice training is highly focused on providing support to the family and being family oriented; this is considered just as important as support to the patient. The gerontology and hospice literature lacks a focus on research about people who are approaching the end of life with no family. Research on end-of-life care for people with no family is increasingly important due to growing demographic trends over recent decades; it is becoming more common for people to age without children, whether by choice or due to circumstances. Choosing childlessness as a lifestyle has become more appealing to individuals; younger generations are often choosing to focus on becoming successful in their careers. Choosing not to get married or have children is becoming more normalized (Tunalilar, 2016). In fact, the current estimate of childless older adults (those aged 65 years and older) in the United 
States range from 15\% to 20\% (Call \& Koropeckyj-Cox, 2007). With current trends, these percentages of childless individuals will continue to rise. Although research shows that friends, neighbors, and distant kin are likely to take on care in emergencies, this care is more likely to be short term and less intense than that provided to a parent by their adult children (Wenger, 2009).

The role health care professionals play in taking care of the needs of individuals who don't have family during their dying process is an area that needs to be explored. No research was located for this thesis that examined hospice for people who do not have children or other family members supporting them and helping them through their end-of-life journey. A nursing textbook, Family Health Care Nursing (Robinson et al, 2018), has a chapter about how to be a nurse in palliative care and it focuses mainly on family support, how to work with the family, and be there for them through their loved one's end of life journey. It did not include how to support a patient without a family.

Studies have shown that a good relationship between the resident and the nurse is crucial for quality patient care (Cartwright et al, 2016). Again, these studies only focused on patients with family, so the patient's relationship with the nurse may be much different than in a patient without kids, spouses, and siblings to care for them. This research aims to explore how the relationship between a nurse and resident may differ for those with and without family and, if so, in what ways.

\section{Preliminary Research}

\section{Research Method}

An exploratory study will be conducted to gain a better understanding of this understudied topic from the perspective of older adults who do not have family. Exploratory research is used to determine what information is missing from the literature and lay the 
groundwork that will inform future studies (Exploratory Research, 2019). To gain an understanding and provide insight into these relationships, a qualitative research design was chosen. To help focus this research, the decision was made to conduct interviews in assisted living settings along with shadowing of the nurses. Assisted living was chosen because individuals without families are overrepresented in these settings and nurses are available. This setting is accessible to students.

Interviews will be conducted with 1-4 residents without family who have serious health conditions and with the nurses who care for them. The residents will be asked in-depth questions about their relationship with nurses and the impact that has on their care experience. Although criteria for recruitment did not require that residents be hospice patients, talking to residents with serious illnesses will provide insight into the role of a nurse with those nearing the end of life. The nurse interviews will give insight into a complete understanding of the nurse-resident relationship beyond the surface-level observations of care gained from shadowing.

In addition to interviews, the observation component will also give context into daily care and relationships. Shadowing will provide the student researcher with more information about the context of care since the student does not have prior experience in the setting. Observation for this study involves shadowing nurses as they interact with and provide care to the residents participating in the study. Seeing the interactions of the nurse with patients with and without families will allow identification of any differences that are occurring.

\section{IRB Approval}

Approval for this study was obtained from The Institutional Review Board (IRB), an administrative body that reviews research to assure application of research ethics. The primary purpose of the IRB is to protect the rights of human subjects involved in research activities. They 
review potential challenges and risks to research subjects and determine if the risks are minimal and reasonable in relation to the anticipated benefits. The IRB also ensures that the privacy and confidentiality of the subjects are protected (IRB Review Process 2020). Along with protecting the research participants, they also look at the proposed methods and ensure that it is the highest quality (Enfield \& Tuwit, 2008).

After the research questions were chosen and the methods were identified, IRB approval was required before the research could begin. Four forms were required and completed that describe the research proposal to be reviewed. Form One is a project overview discussing the objectives, rationale, and subject procedures without going into the specifics of each (Appendix A). Form Two is for certain types of research with human subjects who pose low risk and may be exempt from review. However, because this research involved people at the end of life, a review was required. Form Three provides details about all aspects of the research: research subject population, recruitment, consent/assent, study design and methodology, research setting, data management, confidentiality of data and privacy of subject, risk and benefits, and resources and qualifications (Appendix B). Also included in this review are the research questions, consent forms, and documentation of approval from the facility which is all discussed more at length below. The fourth and final form is an investigator assurance review to ensure that each investigator complies with policies and requirements of the Office of Research Integrity (Appendix C). All of these documents were submitted to the IRB for review. Oftentimes the board requests clarifications and additions to be included before the research will be approved. After a few resubmissions, the proposed research was approved by the IRB. 


\section{Recruitment}

As stated above, it is less common for a person to reach the end of life and not have any family involved in their care. When choosing the location for the research, it had to be certain that there were people who matched the demographic that was the focus of research. Terwilliger Plaza is a non-profit continuing care retirement center (CCRC) that includes assisted living as one component of its services. This means that people must buy in and have the resources to live in this facility. As a nonprofit CCRC, it has a high nurse to resident ratio. Terwilliger Plaza administration is open to research and student study. For these reasons and its location near Portland State University, Terwilliger Plaza was approached, and the administrator of the assisted living facility program agreed to support the project.

The minimum age of admission for Terwilliger Plaza is 62 although the average age of admission is 82 . This assured that all residents participating in the research would be over the age of 62 and would most likely be in their 80 's or older. The residents recruited for the research were identified by a social worker at Terwilliger Plaza. To keep this small study as consistent as possible, all residents chosen were self-identifying women. In addition, women are overrepresented in assisted living settings. Participants without any cognitive impairments were chosen so they could provide informed consent and fully discuss questions about their health and relationships in detail. Participants with proficiency in English were chosen; they did not need to be native English speakers, but they needed to be able to communicate clearly and have a conversation with an English speaker. A small sample size of 1-4 residents was chosen because this research was being done as a student project to expand the knowledge of the researcher in the nursing field and end-of-life care from the perspectives of residents who will receive that 
care. The small sample size was also selected because of the limited time frame; just enough residents were chosen to get enough in-depth data without a lengthy and costly timeline.

Following recruitment, the social worker provided residents with the consent form to review (Appendix E). This gave them a further understanding and background of the research being conducted. The residents were assured that participation is voluntary, confidential, and that they could withdraw at any time without effect on the research being done. The research protocol required that the consent form be signed at the time of the interview. Due to extreme circumstances of COVID-19, however, the interviews had to be put on hold.

\section{$\underline{\text { Research Design Implementation }}$}

The following section describes IRB approved plans to conduct the research. Although it could not be completed at this time, the author still intends to conduct the research as described. The research design has two major parts, shadowing nurses and conducting interviews with residents. Each will be described below.

\section{Shadowing}

It was discussed at length whether shadowing the nurses should be included in this project, but ultimately it was decided that it was an important way for the researcher to grasp an understanding of the daily role of an assisted living nurse. Not only will this gain insight into residents involved in this research, but to observe their role in all residents' lives, what their relationships look like, and the different interactions between people with and without family. This is not a main focus in the research and is not going to be analyzed but will provide important information about the context of end-of-life care from a nurse's perspective. Apart from providing context, observation provides an opportunity to meet the resident and get acquainted. It is a great time to answer any questions from residents about the study, discuss 
when the interviews will be conducted, where they are most comfortable talking, and the length of the interview.

\section{Interview Questions}

Interviews with the residents and nurses will be audio recorded and notes will be taken to get an accurate record of the interview. Listening to recordings will allow the researcher to pay additional attention to things such as tone of voice and ease of answering questions, which will help in interpreting their responses. Notes can serve as backup to the recordings but can also include important thoughts, help highlight key points, and discuss observations that may not be reflected in the audio. This information, in addition to the transcripts (e.g., the way they sound, whether they had difficulty with a question, and the overall take home of the interview) will be important during analysis.

All recordings and notes will be transcribed and secured in compliance with IRB requirements. Each question was crafted to gain insight into the nurse and resident's relationship and how that pertains to the quality of end-of-life care (Appendix G). The residents will be asked first about what a day at Terwilliger Plaza looks like and the interactions they have with others. This will provide information about how often they are exposed to their health care providers, their friends, and others they interact with, signifying satisfaction with their overall quality of life and relationships. Next, the residents will be asked specifically about their relationship with the nurses and the physical and emotional support that nurses provide. Follow-up questions will include probes about the kinds of conversations that take place, if they are excited to see their nurse, and how well they know each other. Relationship strength can say a lot about the care someone receives and the importance of that relationship shows how nurse caregivers can influence the satisfaction of their care. Next, the residents will be asked about the support that 
they receive outside of the care facility from friends and others to see where the residents are receiving care from and the kind of influence those supporters have on their care. Without strong family support, it is important to see how the health care professionals provide supplemental support. Finally, residents will be asked the key question of the research: do they think their care experience is different than people with family? Identifying key differences in care and support between the two populations will allow areas to be identified where nurses may need to adapt their services to meet the needs of the population.

The interviews with the nurses will be a little less formal so the questions are less structured (Appendix H). They will be asked about their daily rounds to provide background information about the care they give and how that is provided to the residents. Quality care not only shows how the nurse's provide care, but their definitions of quality care can be compared to that of the residents. The difference in their definition can give insight into the care that is being provided and whether it is considered quality care. Lastly, they will be asked specifically about the difference between residents with and without family. The nurses engage with these residents firsthand so their responses will be a good indicator of the difference in support these two populations receive.

\section{Analysis}

All the transcriptions and notes from the interviews will be read multiple times to gain a sense of what it contains. The data will be coded into themes according to different categories such as care received/quality care, support, relationships, groups/activities, and needs improvement. Some themes may overlap or emerge throughout the process, but each will be distinguished and placed into the identified category. By looking at the recurring themes of the care and relationships and seeing if the two are connected with nurses and people without family, 
the relationship between nurses and individuals without family can be examined to determine if this dynamic influences their palliative care.

Results from this analysis of qualitative data will be used to refine research questions for future studies. Doing this proposed research would allow us to see if we are asking the right questions and whether there are other issues to be considered. As new questions arise, a potentially larger scale qualitative study might emerge that allows a more targeted study.

\section{$\underline{\text { Reflection }}$}

This study presented many difficulties, most related to the IRB. The IRB requires incredibly detailed information that I would not have considered otherwise. Shadowing the nurses became an issue when getting approval from the IRB because they wanted detailed data collection and analysis information. If the data on shadowing were being used in analysis, they required a section in the IRB for behavior style coding, analysis of field notes, and the qualitative coding procedures. Their concerns helped us to think through the purpose of the shadowing. As a result, the decision was to use shadowing data only as baseline knowledge for student learning purposes, which means these additional sections did not need to be added.

Difficulties with the original consent form, which was based on forms used previously by the Institute on Aging, also emerged. It turned out that there is a formal template that the IRB now requires (Appendix D). It was difficult to make the decision to provide the new consent form to the participants because it was more formal and difficult to follow. It was a concern that it would turn participants away from the research and they would decide not to partake in the interview. Ultimately, however, to get approval for the research, the new format was used.

Although writing the IRB and conveying precise details about every aspect of the research was difficult, it helped clarify our thinking about the scope and purpose of each 
component of the research. The IRB forms had to be edited and reconsidered multiple times, but it was finally approved after a few months of edits. Although this research could not be done in real time due to extreme circumstances, the research is important because this population of individuals without family at the end of life is growing and their needs are not well understood. It was predicted that this exploratory research would show insight into unique roles of nurses in working with individuals at the end of life without families. Support from the nurses was expected to show a positive influence on the residents who don't receive support from family. This study will help the researcher gain more insight into positive and/or negative aspects of the relationship with nurses and the care received. Going through the end of life without someone there to help with treatment plans, to support emotional needs, to talk and reflect on life can decrease the quality of life. Although this sample study is too small to draw conclusions, it can begin to shed light on support necessary to provide quality end-of-life care to individuals without family. 


\section{Bibliography}

Call, V. R. A., Koropeckyj-Cox, T., (2007) "Characteristics of older childless persons and parents: Cross-national comparison.” Journal of Family Issues, 28,1362-1414.

Cartwright, J. C., Miller, L., Volphine, M., (2009). "Hospice in Assisted Living: Promoting Good Quality Care at End of Life." The Gerontologist, vol. 49, no. 4, 2009, pp. 508-516.

Enfield, K., Tuuwit, J. (2008, October). The Purpose, Composition, and Function of an Institutional Review Board: Balancing Priorities. Retrieved May 21, 2020, from https://pubmed.ncbi.nlm.nih.gov/18811996/

Exploratory Research - Research-Methodology. (2019). Retrieved May 20, 2020, from https://research-methodology.net/research-methodology/researchdesign/exploratory-research/

Gawande, A., (2014) Being Mortal: Medicine and What Matters in the End . Picador.

IRB Review Process. (2020). Retrieved from https://research-compliance.umich.edu/humansubjects/irb-health-sciences-and-behavioral-sciences-hsbs/irb-review-process

Robinson, C. A., Robinson M., Steele, R., Widger, K. A. (2018). Families in Palliative and Endof-Life Care. In D. P. Coehlo, V. Gedaly-Duff, S. M. H. Hanson \& J. Kaakinen (Eds.), Family Health Care Nursing: Theory, Practice, Research (6th ed., pp. 279-309). F.A. Davis Company.

Tunalilar, O. (2016). Childlessness, Voluntary. In C. L. Shehan (Ed.), Encyclopedia of Family Studies (pp. 1-5). Hoboken, NJ, USA: John Wiley \& Sons, Inc. Available from https://doi.org/10.1002/9781119085621.wbefs 199

Wenger, C. G., (2009). "Childlessness at the end of life: evidence from rural Wales." Cambridge University Press, Ageing \& Society vol. 29, pp. 1243-1259. 
Appendix A

IRB Form 1: Overview \& Pre-Screening

Human Research Protection Review

FORM 1: OVERVIEW \& PRE-SCREENING

\section{SECTION 1: PROJECT OVERVIEW}

A. Project Title: The Role of a Nurse in the End-of-Life Experience of People Who Don't Have Family.

B. Study Lead: Student Investigator with Faculty Advisor

C. Investigator(s):

\begin{tabular}{|l|l|l|l|l|c|}
\hline Name & $\begin{array}{c}\text { Department } \\
\text { or Other } \\
\text { Affiliation }\end{array}$ & Email & $\begin{array}{c}\text { PSU } \\
\text { Affiliation }\end{array}$ & Project Role & $\begin{array}{c}\text { CITI Training } \\
\text { Date* }\end{array}$ \\
\hline $\begin{array}{l}\text { Laurynn } \\
\text { Leonard }\end{array}$ & $\begin{array}{l}\text { Honors } \\
\text { College }\end{array}$ & laurynn@pdx.edu & Student & Study Lead & $11 / 11 / 19$ \\
\hline Diana White & $\begin{array}{c}\text { Institute on } \\
\text { Aging }\end{array}$ & dwhi@pdx.edu & Faculty & $\begin{array}{c}\text { Faculty } \\
\text { Advisor }\end{array}$ & $03 / 22 / 17$ \\
\hline & & & & & \\
\hline & & & & & \\
\hline
\end{tabular}

*Application will not be processed until the $\mathrm{PI}, \mathrm{Co}-\mathrm{I}$, Student Investigator or other Key Personnel listed have completed CITI Training.

D. Student Investigator: A faculty advisor MUST be identified above.

Is this project the subject of student's master's thesis or dissertation?

Yes $\underline{\text { No }}$

E. Funding: Is the proposed project funded through external funding source(s)? Yes No List Funding Source(s):

Provide PSU Proposal \# or Banner Grant \#: 
F. Financial Conflict of Interest: Do any of the investigators have an economic interest in, or act as an officer or director of, any outside entity whose financial interest would reasonably appear to be affected by the results of the study? Yes $\underline{\text { No }}$ If yes, describe:

G. Proposed Project Duration: Anticipated Start Date: January 2020

Total Project Duration (\# of months): 2 months

H. Objectives: State the purpose and specific aims of the study; include the hypotheses to be tested or the research questions that will guide the study. Use plain language and keep description brief; suggest use of bullet points or list format.

The purpose of this study is to see how the relationship between a nurse and a patient with no family influences their end-of-life experience.

These experiences will be compared to the literature that describes relationships between nurses and people with family. Differences will be identified and procedures to support those individuals with no family will be discussed.

I. Rationale: Provide the scientific or scholarly background for, rationale for, and significance of the proposed study based on existing literature and explain how it will add to existing knowledge. Briefly summarize the relevant current context of the study and gaps in current knowledge. Use plain language and keep explanation brief; suggest use of bullet points or list format.

Literature on hospice and working with people at the end of life is heavily focused on family. A major focus around end of life care is how to support the family, the family role, and the influence the family has on the patient. There is a lack of knowledge in the literature about patient care of those who have no family (no spouse, no children, no siblings). It is not known if there is a difference between the relationships built around care at the end of life differs for people who do not have that family support.

As a pre-nursing student, I am interested in exploring those differences. And as an aspiring health care provider, I am interested to see the comparison in emotional care that persons with no family needs from the people with family support.

This knowledge will allow an insight into how people with no family differ and how future health professionals can provide the best care they can to that underrepresented demographic.

J. Subject Procedures: Briefly describe proposed study activities and indicate how project data will be gathered or generated (i.e., use of existing data, observation, surveys, interviews, experimental/control 
procedures, etc.). Describe how the investigator will recruit subjects to participate and explain consent/assent procedures, if applicable.

Participants will be recruited by social workers and nursing staff who worked at the Terwilliger Plaza and know their health care plans. They will recruit people from their assisted living unit who don't have any family and do not have any cognitive impairments.

Each participant will be interviewed. I will observe the nurse and patient interaction and the care that is provided. The nurses providing the care will also be interviewed informally about their experiences working with residents with and without family.

\section{SECTION 2: HUMAN SUBJECTS RESEARCH PRE-SCREENING}

\section{A. RESEARCH DETERMINATION}

1. Is the project intended to be an investigation, a searching inquiry to gather facts, or an examination of a phenomenon?

2. Is it systematic; involving a system, method, or plan that will be employed consistently throughout data collection?

3. Are the results of the project expected to expand the knowledge base of a scientific discipline, or other scholarly field or study, and be publicly disseminated so that the results can be used to develop, test, or support theories, principles, and statements of relationships or inform policy beyond the study?

4. Will the results be applicable to a larger population beyond the site of data collection or the individual subjects? (Check "No" if the conclusions will apply only to the sample population). 
If the answer to ALL questions in Section $2 A$ are NO, it is likely the project does NOT meet the federal definition of research and IRB review is not required. Email this completed form to Research Integrity at psuirb@pdx.edu for confirmation.

If the answer to ANY of the questions in Section $2 A$ is YES, it is possible this project meets the definition of research. Additional information is required. Proceed to Section $2 B$ of this form.

\section{B. HUMAN SUBJECTS DETERMINATION}

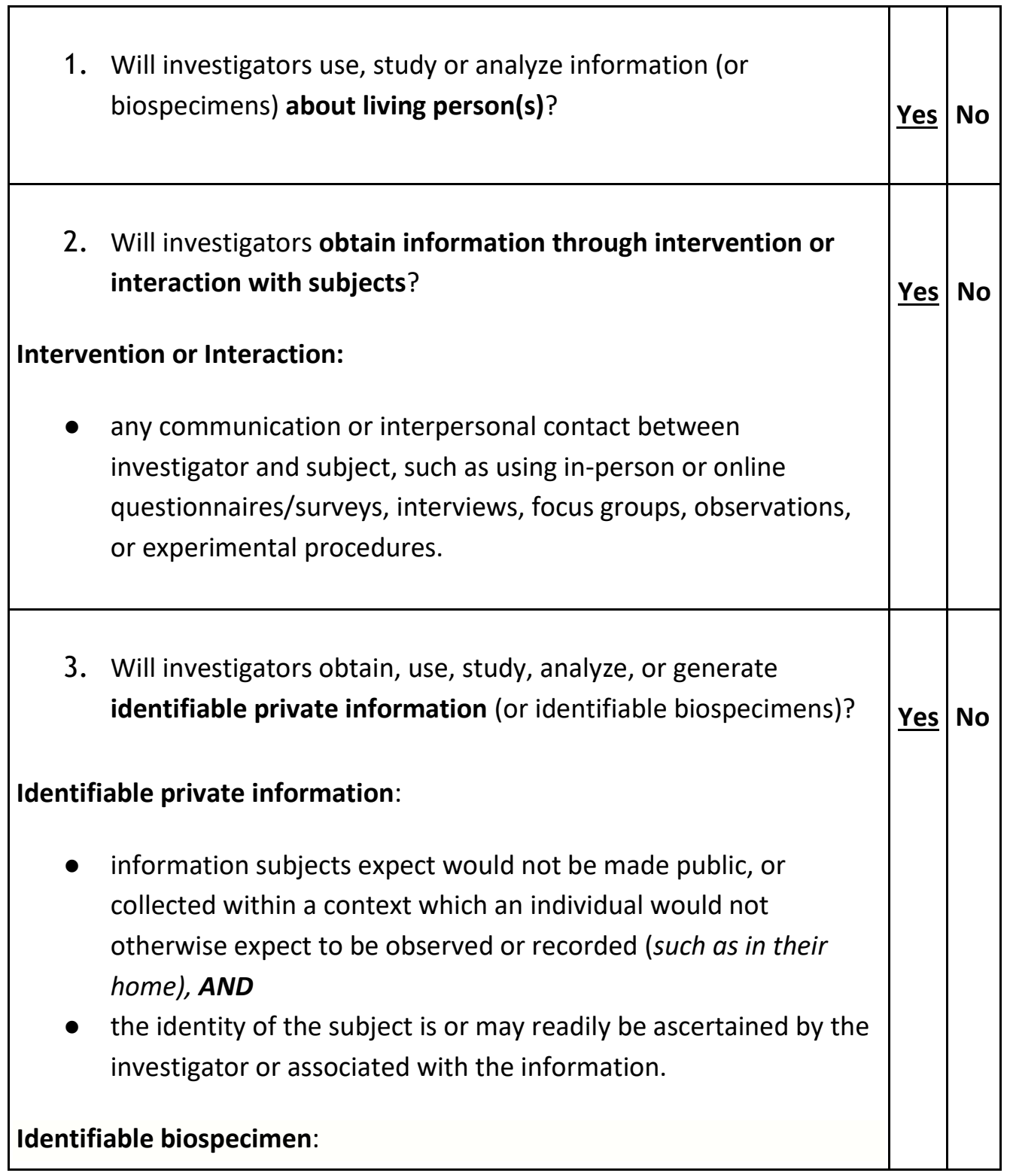


- biospecimen for which the identity of the subject is associated with the biospecimen or may readily be ascertained by the investigator.

If the answer to ALL questions in Section $2 B$ are NO, it is likely the research does NOT meet the federal definition of human subjects and IRB review is not required. Email this completed form to Research Integrity at psuirb@pdx.edu for confirmation.

If the answer to Question 1 in Section 2B is YES and either Question 2 or Question 3 are also marked YES, the research involves human subjects. Additional information is required:

- Form 1: Project Overview \& Pre-Screening is now complete; retain form for submission.

- Complete Form 2: Exemption Certification to determine if the project qualifies as exempt. NOTE: In the Revised Common Rule, previously expedited research is now exempt. 
Appendix B

IRB Form 3: Initial IRB Review

\section{Human Research Protection Review}

3: INITIAL IRB REVIEW

Important: Complete this form ONLY if the project does not meet the criteria for exempt review, as outlined in Form 2: Exemption Certification. If the research requires IRB review, this form must be completed, and all applicable attachments and research materials submitted.

This study will involve (select all that apply):

- Collection of information through intervention/interaction with subjects

Analysis of existing data (if ONLY existing data will be used, SKIP Section 2 and Section 3 below)

\section{SECTION 1: RESEARCH SUBJECT POPULATION}

A. Describe the individuals about whom information will be collected or from whom specimens will be collected:

1-4 women residents from Terwilliger Plaza will be interviewed. Each resident lives in assisted living with nurses available 24/7. These residents have no immediate family support for care, although they each have a friend who helps with care.

1-3 nurses from Terwilliger Plaza will be interviewed. Each nurse has direct access to each of the residents who will be interviewed.

B. Will the subjects include any of the following vulnerable populations? Select all that apply.

\section{Non-English Speaking Subjects}

If yes, indicate the language(s) spoken by subjects and whether translators/translations for participation will be needed:

2. Children (subjects under 18 years of age)

If yes, complete the Research With Children Form

3. Prisoners 


\begin{tabular}{|l|l|l|}
\hline If yes, complete the Research with Prisoners Form & & \\
\hline 4. Individuals with Impaired Decisions-making Capacity & Yes & No \\
$\begin{array}{l}\text { If yes, describe the impaired decision-making capacity of subjects and } \\
\text { whether they require a legal guardian or representative to participate: }\end{array}$ & \\
\hline $\begin{array}{l}\text { 5. Economically or Educationally Disadvantaged Persons } \\
\text { If yes, describe the economic or educational disadvantage of the }\end{array}$ & Yes & No \\
\end{tabular}

C. Describe the rationale for selecting the subject population: Include in the response the criteria (such as age range, gender, language, etc.) that define who will be included in the study sample, and the reason for selecting the population(s). Specifically describe any exclusion criteria and rationale.

Residents in assisted living were chosen because we are specifically looking at the end of life experience. The minimum age of admission for Terwilliger Plaza is 62 years of age; the average age of admission is 82 and above so participants likely will be considerably older than 62 .

Residents with no family were chosen because we are looking at the relationships between nurses and residents with no family.

We decided to interview women only to reduce variability. The way women and men feel and respond to questions about life care situations may differ, so in this pilot study, it was important to interview participants of the same sex. In addition, women are over-represented in assisted living settings.

Participants without any cognitive impairments were chosen so they are able to facilitate informed consent and to discuss questions about their relationships in detail.

Participants will be chosen on their proficiency in English. They do not need to be native English speakers, but they must be able to communicate clearly and have a conversation with an English speaker. 


\section{Sample Size: 5}

E. Provide a justification for the sample size: Explain why this sample size was chosen; if applicable, provide details of the power analysis conducted that justifies the selected sample size.

The small sample size of 1-4 residents was chosen because this is a student project.

It is being done as an exploratory research project to expand the student's

knowledge of the nursing field and end-of-life care from the perspectives of residents who will receive that care. It must be done in a limited time frame, so just enough residents were chosen to get enough in-depth data without a lengthy and costly timeline.

\section{SECTION 2: RECRUITMENT}

A. Describe when, where, and how potential subjects will be identified for participation in the study:

Participants will be identified by social workers at Terwilliger Plaza. The social work staff know the health care plans of each resident and know which residents do not have family support. They will reach out to them, propose the research, and get their consent by December 31, 2019. If the residents agree, I will meet them briefly upon approval of the IRB to introduce myself and get acquainted before conducting the interviews.

B. How will potential subjects be contacted to participate in the study? Select one or more of the following and submit a copy of each with this form.

$\square$ Brochures

$\square$ Flyers

$\square$ Emails / Letters

$\square$ Newspaper or Magazine Advertisements

$\square$ Radio or Television Announcements

$\square$ In Person Verbal Scripts

$\square$ Website / Social Media Outlets

- Other, describe: Personal recruitment from social workers who know their living situation personally.

\section{Will subjects be compensated for participation in the study? Yes No}

If yes, describe the amount and timing of any payments to subjects: 


\section{Will pre-screening of potential subjects take place?}

Yes No

If yes, describe the criteria used to screen subjects and attach screening tool:

The participant must have no family and no cognitive impairment.

Screening will be done by the social worker on staff who knows each resident's

health care plan personally.

\section{SECTION 3: CONSENT / ASSENT}

A. From whom will consent/assent be obtained? Select all that apply.

- Consent from Subject

$\square$ Assent from Child

$\square$ Assent from Individuals with Impaired Decision-making Capacity

$\square$ Permission from Parent, Guardian or Legally Authorized Representative

B. How will consent/assent be addressed? Select one or more of the following.

\section{- Written Documentation of Consent or Assent}

*Signed consent or assent forms obtained by researcher.

$\square$ Waiver of Documented Consent or Assent

*Written/verbal consent or assent statement provided to subjects, no signatures obtained.

$\square \quad$ Alteration of Some OR Waiver of All Informed Consent Requirements

*No consent or assent procedure, or the consent procedure does not fully disclose all required elements of the research (e.g., deception research).

*If this option is selected, complete the Consent Alteration or Waiver Form.

C. Describe how consent/assent will be obtained: Include in the response who will obtain consent/assent, where the consent process will take place, and the steps that will be taken to ensure the subjects' understanding of the study and procedures. If applicable, address how consent/assent procedures may be impacted if any subjects are vulnerable populations.

The consent form will be given to participants by the social worker before the interview. At the time of the interview, the interviewer will read the consent aloud and obtain a signature before the interview starts. 
D. Describe the steps that will be taken to minimize the possibility of coercion or undue influence, particularly when subjects are from vulnerable populations:

Residents will be assured that participation is voluntary, confidential, and that the participant can withdraw at any time without affecting their care at Terwilliger Plaza, the interviewer's opinion of them, or the research that is being done.

\section{SECTION 4: STUDY DESIGN AND METHODOLOGY}

A. Provide a description of all research procedures and activities, including a timeline for each of the research activities:

Week 1: Interview the nurses and talk about their relationships with residents and the role they play in their life and/or health care.

Week 2: Observation of nurses as they provide their daily care to the residents and watch what each interaction looks like compared to the next, the conversations that take place, and the residents' reaction to the care.

Week 3-4: Interviews with Residents about their relationships with the nurses and how that relationship influences the care that they are receiving.

B. Describe what data (and/or specimens) will be collected directly from subjects and how it will be collected at all measurement/data collection time-points: Include in the response a description of the instruments, source records or measures that will be used to collect data about participants.

See attachments for questions being used to collect data from participants.

C. Describe the duration of an individual subject's participation in the study (not applicable for data analysis only research): 
Each interview will last between 30-60 minutes unless the resident decides to end early, gets tired, or feels uncomfortable. At that point, the interview will end before the suggested time.

D. Describe any anticipated circumstances under which subjects will be withdrawn from the research without their consent (if applicable):

N/A

E. Describe procedures that will be followed when a subject withdraws from the research, including partial withdrawal from the study (if applicable):

Residents may decide to conclude the interview early. The resident will be thanked for their time and the interview will come to an end. They will be reminded that there is no penalty for withdrawing from the research. Talking may continue if it seems appropriate but will not be added to collected information for the research.

\section{F. Will the study also involve examination of secondary data? Yes No}

If yes, describe the secondary dataset. Include the response the source of the data, the process for acquiring approval to use the data, including whether any data use agreements, authorization or special permission is required to obtain the data.

G. Which of the following instruments will be used? Select one or more of the following and submit a copy of each with this form.

$\square$ Surveys / Questionnaires

- Interview Questions / Protocol

- Behavioral Observation Tools

$\square$ Intervention Tools / Materials

$\square$ Other, describe:

H. Will the study involve audio/video recordings or photographs?

Yes No

If yes, describe how and what activities will be recorded, along with the process for obtaining permission to record/photograph and use the recordings/photographs. 
The participant will be asked if they are comfortable being audio recorded. If they answer yes, I will start the recording and ask again to show proof of verbal consent on the recording. I will record the interviews of residents to make sure I get all the information right.

I. Will the study involve drugs/substances or investigational devices:

Select all that apply; if yes, complete the Drugs and Devices Form.

\section{SECTION 5: RESEARCH SETTING}

A. Describe the location(s) where the research procedures will take place:

Interviews will take place at Terwilliger Plaza, 2545 SW Terwilliger Blvd, Portland, OR 97201 . This is where the residents live; interviews will be conducted in their room or where the resident feels most comfortable.

B. Describe any location-specific requirements, regulations, and/or customs affecting the research: Include in the response any site-specific regulations or permissions such as approval from other compliance or ethics committees.

N/A

C. Will the study be conducted in whole or in part outside the United States? Yes No If yes, complete and submit International Research Form.

D. Will the study be conducted at multiple sites?

Yes No If yes, list the external sites and explain what activities will occur at each site; describe plans for communication among the sites regarding adverse events, interim results, protocol modifications, and monitoring of data. Include in the response if PSU will serve as the IRB of Record and if so, submit the IRB Authorization Agreement Request Form. 


\section{SECTION 6: DATA MANAGEMENT}

A. Describe the data analysis plan: Include in the response any statistical and quality control procedures.

The recordings will be checked after interviews. If recording fails then the notes will be checked immediately and everything that can be remembered from the interview will be written down.

Residents' names and any other identifiable information will be excluded from any notes.

B. Describe how data (and/or specimens) will be stored: Include in the response who will have access to the data (and/or specimens), where and how long it will be stored. If the data (and/or specimens will be transported, describe who will be responsible for receipt and transmission.

Records of recording will be downloaded onto a password protected personal computer that only I have access to. Handwritten notes will be taken and stored in a locked room and only taken out when studying the information in a private location.

Obtained information will only be shared with Diana White, the faculty supervisor.

\section{Will the data (and/or specimens) be banked for future use? Yes No}

If yes, describe the procedures to release data or specimens, including the process to request a release, approvals required for release, who can obtain data or specimens, and the data to be provided with specimens.

\section{Does the study require a Data Safety Monitoring Plan (DSMP)? Yes No} If yes, submit the Data Safety Monitoring Plan.

\section{SECTION 7: CONFIDENTIALITY OF DATA \& PRIVACY OF SUBJECTS}

A. Describe procedures for maintaining confidentiality of data: Include in the response the steps that will be taken secure the data (e.g., training, authorization of access, password protection, encryption, physical controls, certificates of confidentiality, and separation of identifiers and data) during storage, use, and transmission. 
The personal computer used is protected with a password that other individuals do not have access to. The room with stored notes will be locked at all times. The information given to Diana White will only be shown as hard copies. All names and identifiers will be taken out of any documents and will not be included in any of the data.

B. Describe provisions to protect subjects' privacy (their desire to place limits on whom they interact or provide personal information) and to minimize any sense of intrusiveness that may be caused by study questions or procedures:

Participants can decide not to answer questions that they don't feel comfortable answering. Not answering a question does not mean they will be disqualified from the interview/research. Remind participants that their answers will be used as a student research project to gain knowledge in the nursing field.

\section{SECTION 8: RISKS \& BENEFITS}

A. List the reasonably foreseeable risks, discomforts, hazards, or inconveniences to the subjects related to their participation in the research: Include in the response the probability, magnitude, duration, and reversibility of the risks. The nature of the risks may be physical, psychological, social, legal, and economic including those resulting from breach of data confidentiality or invasion of privacy.

There may be discomfort with some of the questions asked. If residents show signs or discomfort or verbalize that they are uncomfortable, then we will move onto another topic of discussion. If it seems like there is severe discomfort then we can choose to end the interview and reschedule for another time. At that point, the questions will be reviewed and edited to provide less stress on the participant. The resident may also choose to withdraw from the study.

B. Describe how the potential risks of the study will be minimized in order to protect subjects' rights and welfare:

There may be discussion of personal things that can lead to an emotional response or discomfort. When interviewing, I will be sensitive to stopping and reminding the participant that their participation is voluntary and that they may stop the interview with no negative consequences. 
C. Describe the potential benefits that individual subjects may experience from taking part in the research: Include in the response the probability, magnitude, and duration of the potential benefits. Do not include benefits to society or others. Indicate if there is no direct benefit.

Participants will have an opportunity to share their stories and contribute to training the next generation of nurses. By telling their story and talking about their care, the student researcher will learn how to support this demographic of elders and be better prepared to provide the best care to individuals without families.

\section{SECTION 9: RESOURCES \& QUALIFICATIONS}

A. Describe the qualifications (e.g. training, experience) of the investigators listed in Form 1: Project Overview \& Pre-Screening as it relates to their ability to carry out the proposed research:

Both investigators have completed the CITI training.

Ms. Leonard has volunteered with hospice for over a year. She is an undergraduate in the honors college at Portland State University studying prenursing.

Dr. White is an experienced researcher and professor at the Institute of Aging at Portland State University. She has served as PI on several studies with residents in long-term care settings, receiving IRB approval for these studies.

B. List the key research roles in addition to the investigators listed in Form 1: Project Overview \& PreScreening and describe the process to ensure that all persons assisting with the research are adequately informed about the protocol, the research procedures, and their duties and functions: Describe specific research/study personnel roles, do not provide individual names.

Study Lead is exploring a student project through the honors college for their senior thesis.

Faculty Advisor is providing expertise, support, and direction to the student researcher.

C. Are any study personnel on the study external to, or not affiliated with, PSU? Yes No If yes, provide the name of the individual, their affiliation and their role on the project. 
D. Describe how the research facilities and equipment at the research site(s) support the study's aims (e.g., private interview rooms, etc.):

The private resident rooms will provide comfort and confidentiality to the participants.

E. Describe the availability of medical or psychological resources that subjects might need as a result of an anticipated consequences of the human research, such as procedure debriefing and/or counseling resources.

There is a nurse on staff at all times. If emotional counseling is needed there is a social worker on staff who works directly with residents.

\section{SECTION 10: Protocol Submission}

To request Initial IRB Review for the proposed research, email the PSU Office of Research Integrity at hsrrc@pdx.edu with the following completed materials attached (check all that apply):

- Required: Form 1: Project Overview \& Pre-Screening (completed in Step 1)

- Required: Form 3: Initial IRB Review (this form)

- Required: Form 4: Investigator Assurance

$\square$ Recruitment Materials (if applicable, as noted in Section 2 above)

- Consent Materials (if applicable, as noted in Section 3 above)

$\square$ Instruments / Data Collection Tools (if applicable, as noted in Section 4 above)

- Data Use Agreement(s) or other documentation of permission (as applicable)

Supplemental Forms, if applicable: 
Appendix C

IRB Form 4: Investigator Assurance

\section{Human Research Protection Review FORM 4: INVESTIGATOR ASSURANCE}

Important: The Principal Investigator (and Student Investigator) must review each of the investigator responsibilities outlined below and check each box when understood. Each box must be checked in order for the submission to be processed by ORI.

\section{SECTION 1: INVESTIGATOR RESPONSIBILITIES}

1. I understand PSU's policies concerning research involving human subjects and that I have ultimate responsibility for the protections of the rights and welfare of human participants, the conduct of this study, and the ethical performance of this research.

2. I will maintain IRB related documents (including signed consent forms, as applicable) for a minimum of three years after the completion of the study, or for a minimum of five years after completion if the study is funded (this may vary depending on the funding agency requirements).

3. I understand it is my responsibility to ensure that all study personnel receive the mandatory human subjects' research protection education (CITI Training) and to maintain a training documentation file.

4. I agree to:

- Comply with all PSU HRPP policies, decisions, conditions and requirements.

- Obtain prior approval from the IRB before amending or altering the research protocol or changing the approved consent/assent form.

- Notify the Office of Research Integrity of any related financial conflict not already disclosed.

- Notify the Office of Research Integrity (and when applicable, the granting agency) of all adverse events, unanticipated problems, or protocol deviations in a timely manner.

5. I certify that:

- This research will be conducted in accordance with the principles of The Belmont Report.

- The time and resources are available to complete this project.

- The equipment, facilities, and procedures to be used in this research meet recognized standards for safety.

- New information that may affect the risk-benefit assessment for this research will be reported to the Office of Research Integrity. 
- Adequate supervision of all research study personnel will be ensured.

- The information provided in this application and all attachments is complete and correct.

\section{SECTION 2: INVESTIGATOR SIGNATURES}

By signing below, the Principal Investigator (and Student Investigator, if applicable) agrees to the list of requirements detailed in the assurance above. PLEASE TYPE NAME BELOW.

Principal Investigator/Faculty Advisor: Diana White

Student Investigator: Laurynn Leonard

Date: 12/06/19

Date: 12/06/19 
Appendix D

Original Consent Form

\section{Dear Participant,}

My name is Laurynn Leonard, and I am working with the Institute on Aging at Portland State University. We are interviewing residents to understand the relationship between residents without immediate family and the nurses in direct care with those residents. As a student in prenursing at the University, my goal is to get insight into these relationships so health care professionals can provide better care for each individual.

This survey is voluntary. You can choose to participate. You do not have to be in this study. If you are or if you are not, it will not affect your relationship with the staff here at all. This interview will take about an hour. You can also decide to stop this interview at any time. You can take a break or rest at any time during this interview. If you need to take a break or go to the restroom, just let me know, and we'll stop.

We will be talking to a few residents in this community. There are no right or wrong answers to the questions. I will ask you questions and your answer will be recorded while I take notes. Please answer the questions as honestly as you can.

Protecting the confidentiality of people's answers is very important to me. No one except our research team will ever see your answers. Results will be reported without personal details, and we always make sure that your responses to questions cannot be linked to you.

I do need to let you know that if you talk about being harmed, harming yourself, or harming others, I must report this. This reporting is required by law. I would notify Oregon Department of Human Services staff, who would investigate, while striving to keep your identity confidential. This is the only information that would be shared directly.

If you have concerns or problems about your participation in this study or your right as a research subject, please contact the Office of Research Integrity at 503 725-2227. This office supports the PSU Institutional Review Board (IRB). The IRB is a group of people from PSU and the community who provide independent oversight of safety and ethical issues related to research involving human participants. If you have questions about the study itself, please contact the study's director, Dr. Diana White, 503 725-2725 or dwhi@pdx.edu, or her office: 470P Urban Center, 506 SW Mill Street, Portland, OR 97201.

Do you have any questions? Before we begin, please sign or initial this page. I have a second one for your records. Signing this means that you understand what I have read and agree to take part 
in the study. Please understand that you may stop the interview at any time without penalty and that by signing you are not waiving any legal rights as a research participant.

Participant's Signature or Initials 


\section{Appendix E \\ IRB Consent Form for Residents}

\section{Consent to Participate in Research}

Project Title: The Role of a Nurse in the End-of-Life Experience of People Who Don't Have Family

Population: Women above the age of 60 years old living in assisted living at Terwilliger Plaza. Residents do no have any mental impairments and are without immediate involved in their care. Each residents has volunteered to an hour interview where they will asked about their care and relationship with health care providers. Nurses in direct care of residents being interview will also be interview and asked about the care the residents are receiving.

Researchers: $\quad$ Diana White- Institute on Aging at Portland State University
Laurynn Leonard- Portland State University Honors College

Researcher Contact: Diana White-dwhi@pdx.edu $503725-2725$

Laurynn Leonard- laurynn@pdx.edu $209769-0459$

You are being asked to take part in a research study. The box below highlights key information about this research for you to consider when making a decision whether or not to participate. Carefully review the information provided on this form. Please ask questions about any of the information you do not understand before you decide to participate. 


\section{Key Information for You to Consider}

- Voluntary Consent. You are being asked to volunteer for a research study. It is up to you whether you choose to participate or not. There is no penalty if you choose not to participate or discontinue participation.

- Purpose. The purpose of this research is to understand the relationship between residents without immediate family and the nurses in direct care with those resident. The goal is to get insight into these relationships so health care professionals can provide better care for each individual.

- Duration. Each interview will last between 30-60 minutes unless resident decides to end early, gets tired, or feels uncomfortable. At that point, the interview will end before suggested time. Shadowing will be spread out over a few days with each shadowing lasting about an hours.

- Procedures and Activities. You will be asked a series of questions and a few follow up questions about your care and how having no immediate family has impacted your healthcare experience. I will ask you questions and your answer will be recorded while I take notes. I will also shadow the nurses and observe the care that they provide.

- Risks. Some of the foreseeable risks or discomforts of your participation include discussion of personal things that can lead to an emotional response or discomfort.

- Benefits. Some of the benefits that may be expected include participants having an opportunity to share their stories and contribute to training the next generation of nurses. By telling their story and talking about their care, the student researcher will learn how to support this demographic of elders and be better prepared provide the best care to individuals without families.

- Alternatives. Participation is voluntary and the only alternative is to not participate.

\section{How long will I be in this research?}

We expect that your participation will last a couple of weeks. If time runs out during an interview and there is still information that the participant wants to discuss, another meeting may be set up. Also the nurses involved in the resident's care will be shadowed therefore interactions with the participant may extend over a few weeks.

\section{What happens to the information collected?}

Information collected for this research will be used as a research paper that an be accessed through the Portland State University Library data base. The research paper will not include any personal identifiers and names will be excluded. 


\section{How will my privacy and data confidentiality be protected?}

We will take measures to protect your privacy including downloading recordings onto a password protected personal computer that only the researcher has access to. Handwritten notes will be taken and stored in a locked room and only taken out when studying the information in a private location. The personal computer used is protected with a password that other individuals do not have access to. The room with stored notes will be locked at all times. All names and identifiers will be taken out of any documents and will not be included in any of the data. Despite taking steps to protect your privacy, we can never fully guarantee that your privacy will be protected.

To protect the security of all of your personal information, we will exclude names or personal identifiers from all notes and data collected. Despite these precautions, we can never fully guarantee the confidentiality of all study information.

Individuals and organizations that conduct or monitor this research may be permitted access to inspect research records. This may include private information. These individuals and organizations include the Institutional Review Board that reviewed this research and The Institute of Aging at Portland state University.

\section{What if I want to stop participating in this research?}

Your participation is voluntary. You do not have to take part in this study, but if you do, you may stop at any time. You have the right to choose not to participate in any study activity or completely withdraw from participation at any point without penalty or loss of benefits to which you are otherwise entitled. Your decision whether or not to participate will not affect your relationship with the researchers or Portland State University.

\section{Will I be paid for participating in this research?}

There will be no compensation for participating in this research.

\section{Who can answer my questions about this research?}

If you have questions, concerns, or have experienced a research related injury, contact the research team at:

Diana White Laurynn Leonard

$503725-2725$

dwhi@pdx.edu laurynn@pdx.edu 


\section{Who can I speak to about my rights as a research participant?}

The Portland State University Institutional Review Board ("IRB") is overseeing this research. The IRB is a group of people who independently review research studies to ensure the rights and welfare of participants are protected. The Office of Research Integrity is the office at Portland State University that supports the IRB. If you have questions about your rights, or wish to speak with someone other than the research team, you may contact:

Office of Research Integrity

PO Box 751

Portland, OR 97207-0751

Phone: (503) 725-5484

Toll Free: 1 (877) 480-4400

Email: psuirb@pdx.edu

\section{Consent Statement}

I have had the opportunity to read and consider the information in this form. I have asked any questions necessary to make a decision about my participation. I understand that I can ask additional questions throughout my participation.

By signing below, I understand that I am volunteering to participate in this research. I understand that I am not waiving any legal rights. I have been provided with a copy of this consent form. I understand that if my ability to consent for myself changes, either I or my legal representative may be asked to provide consent prior to me continuing in the study.

I consent to participate in this study.

me of Adult Participant

Signature of Adult Participant

$\mathrm{Na}$

Researcher Signature (to be completed at time of informed consent)

I have explained the research to the participant and answered all of his/her questions. I believe that he/she understands the information described in this consent form and freely consents to participate.

Name of Research Team Member Signature of Research Team Member Date 


\author{
Appendix F \\ IRB Consent Form for Nurses
}

\title{
Consent to Participate in Research
}

Project Title: The Role of a Nurse in the End-of-Life Experience of People Who Don't Have Family

Population: Women above the age of 60 years old living in assisted living at Terwilliger Plaza. Residents do no have any mental impairments and are without immediate involved in their care. Each residents has volunteered to an hour interview where they will asked about their care and relationship with health care providers. Nurses in direct care of residents being interview will also be interview and asked about the care the residents are receiving.

Researchers: $\quad$ Diana White- Institute on Aging at Portland State University
Laurynn Leonard- Portland State University Honors College

Researcher Contact: Diana White-dwhi@pdx.edu $\quad 503$ 725-2725

Laurynn Leonard- laurynn@pdx.edu 209 769-0459

You are being asked to take part in a research study. The box below highlights key information about this research for you to consider when making a decision whether or not to participate. Carefully review the information provided on this form. Please ask questions about any of the information you do not understand before you decide to participate. 


\section{Key Information for You to Consider}

- Voluntary Consent. You are being asked to volunteer for a research study. It is up to you whether you choose to participate or not. There is no penalty if you choose not to participate or discontinue participation.

- Purpose. The purpose of this research is to understand the relationship between residents without immediate family and the nurses in direct care with those resident. The goal is to get insight into these relationships so health care professionals can provide better care for each individual.

- Duration. Each interview will last between 30-60 minutes unless nurse decides to end early, has a resident to attend to, or feels uncomfortable. At that point, the interview will end before suggested time.

- Procedures and Activities. You will be asked a series of questions and a few follow up questions about the care you provide and how care differs between residents who have family and residents who do not have family. I will ask you questions and your answer will be recorded while I take notes.

- Risks. Some of the foreseeable risks or discomforts of your participation include discussion of personal things that can lead to an emotional response or discomfort.

- Benefits. Some of the benefits that may be expected include participants having an opportunity to share their stories and contribute to training the next generation of nurses. By telling their story and talking about the care they provide, the student researcher will learn how to support this demographic of elders and be better prepared provide the best care to individuals without families.

- Alternatives. Participation is voluntary and the only alternative is to not participate.

\section{How long will I be in this research?}

We expect that your participation will last a couple of weeks. If time runs out during an interview and there is still information that the participant wants to discuss, another meeting may be set up. Also the nurses involved in the resident's care will be shadowed therefore interactions with the participant may extend over a few weeks.

\section{What happens to the information collected?}

Information collected for this research will be used as a research paper that an be accessed through the Portland State University Library data base. The research paper will not include any personal identifiers and names will be excluded. 


\section{How will my privacy and data confidentiality be protected?}

We will take measures to protect your privacy including downloading recordings onto a password protected personal computer that only the researcher has access to. Handwritten notes will be taken and stored in a locked room and only taken out when studying the information in a private location. The personal computer used is protected with a password that other individuals do not have access to. The room with stored notes will be locked at all times. All names and identifiers will be taken out of any documents and will not be included in any of the data. Despite taking steps to protect your privacy, we can never fully guarantee that your privacy will be protected.

To protect the security of all of your personal information, we will exclude names or personal identifiers from all notes and data collected. Despite these precautions, we can never fully guarantee the confidentiality of all study information.

Individuals and organizations that conduct or monitor this research may be permitted access to inspect research records. This may include private information. These individuals and organizations include the Institutional Review Board that reviewed this research and The Institute of Aging at Portland state University.

\section{What if I want to stop participating in this research?}

Your participation is voluntary. You do not have to take part in this study, but if you do, you may stop at any time. You have the right to choose not to participate in any study activity or completely withdraw from participation at any point without penalty or loss of benefits to which you are otherwise entitled. Your decision whether or not to participate will not affect your relationship with the researchers or Portland State University.

\section{Will I be paid for participating in this research?}

There will be no compensation for participating in this research.

\section{Who can answer my questions about this research?}

If you have questions, concerns, or have experienced a research related injury, contact the research team at:
Diana White
Laurynn Leonard
503 725-2725
209 769-0459
dwhi@pdx.edu
laurynn@pdx.edu 


\section{Who can I speak to about my rights as a research participant?}

The Portland State University Institutional Review Board ("IRB") is overseeing this research.

The IRB is a group of people who independently review research studies to ensure the rights and welfare of participants are protected. The Office of Research Integrity is the office at Portland State University that supports the IRB. If you have questions about your rights, or wish to speak with someone other than the research team, you may contact:

Office of Research Integrity

PO Box 751

Portland, OR 97207-0751

Phone: (503) 725-5484

Toll Free: 1 (877) 480-4400

Email: psuirb@pdx.edu

\section{Consent Statement}

I have had the opportunity to read and consider the information in this form. I have asked any questions necessary to make a decision about my participation. I understand that I can ask additional questions throughout my participation.

By signing below, I understand that I am volunteering to participate in this research. I understand that I am not waiving any legal rights. I have been provided with a copy of this consent form. I understand that if my ability to consent for myself changes, either I or my legal representative may be asked to provide consent prior to me continuing in the study.

I consent to participate in this study.

Name of Adult Participant Signature of Adult Participant

Date

Researcher Signature (to be completed at time of informed consent) I have explained the research to the participant and answered all of his/her questions. I believe that he/she understands the information described in this consent form and freely consents to participate. 


\section{Appendix G \\ Residents Interview Questions \\ Resident Interview Questions}

Introduction: Thank you for volunteering your time and contributing to my research in expanding knowledge of the influence of nurses in the care of geriatrics without immediate family. I would like to remind you that this is voluntary and you can choose to stop at any point during the interview. The interview will last for about an hour. If you have any questions now or at any point throughout the interview, feel free to ask and I will be happy to answer them.

Is it alright if I record this interview? This will help make sure that I get an accurate record of your thoughts and experiences.

My first question is: What does a typical day look like here? Who do you interact with the most?

Probes: Do you interact most with people from the outside? Other residents?

How often do people from the outside come and visit you? Who are the people who come and visit you?

How often do you do things with other residents? What are the kinds of things you do?

How do your relationships with friends or relatives influence the care you receive?

My second question is: What kinds of things do the nurses do for you?

Probes: Do nurses provide support? What do you wish they would do? [Interested in the dynamics of the relationship]

Are your needs being met?

How well do you know the staff? For example, do you know what nurses' or caregivers' lives outside of the facility?

Do you look forward to seeing your nurse?

What sort of things do you talk about with the nurses? The caregivers?

How often does the nurse stay just to talk? What about the caregivers?

My third question is: Who provides the most support for you now that you live in The Terrace [assisted living]? 
Probes: Who makes decisions about your health and the care that you receive? Are others involved in your health decisions?

Do you discuss those decisions with a nurse?

What makes you feel supported?

If you make your own decisions, how comfortable are you with being the sole decision maker?

My fourth question is: How do you think your experience is similar to or different from other residents who have more family? What is it like to gain support from people who aren't your family?

Conclusion: Thank you for your time. Is there any last question you have for me? 


\section{Appendix $\mathrm{H}$ \\ Nursing Interview Questions}

\section{Nurse Interview Questions}

Introduction: Thank you for volunteering your time and contributing to my research in expanding knowledge of the influence of nurses in the care of geriatrics without immediate family. I would like to remind you that this is voluntary and you can choose to stop at any point during the interview. The interview will last for about an hour. If you have any questions now or at any point throughout the interview, feel free to ask and I will be happy to answer them. Is it alright if I record you?

My first question is: What does your daily routine or rounds look like?

Probes: What are some regulations you have to abide by?

What are some regulations Terwilliger has that influence the care provided?

My second question is: What does quality look like to you?

Probes: What is your favorite part of working here at Terwilliger?

What is your favorite part of being a nurse?

What is the most important part of care to you?

What is it like being a nurse in geriatrics?

My third question is: How does care differ between residents with family?

Probes: Does your care change when there is family around?

How involved is the family with the care?

Does the family and patient often agree on care?

My fourth question is: What does care look like with someone without family?

Probes: Are their needs/ wants different than someone with family?

Do you think that they need more emotional support?

Do you find that their needs are different or that you visit their room more often?

How do their room visits differ from people with family?

My fifth question is: Do you see a difference in the needs or the care provided to people with family and the people without?

Probes: What does your relationship look like with the residents?

How personal is the relationship?

Do you provide anything more than physical support? 
How often do you spend time just sitting, talking, and getting know residents?

Conclusion: Thank you for your time. Is there any last question you have for me? 